\title{
A Preliminary Study of the Relationship between Obliteration of Cranial Sutures and Age at Time of Death
}

\author{
Laura Donato $^{1^{*}}$, Luigi Cipolloni ${ }^{1}$, Al Ozonoff $^{2}$ and Alessandro di Luca ${ }^{3}$ \\ ${ }^{1}$ Department of Legal Medicine University of Rome "Sapienza", Italy \\ ${ }^{2}$ Center for Patient Safety and Quality Research, Boston Children's Hospital, Italy \\ 3 Institute of Public Health, Catholic University "Sacro Cuore" of Rome, Italy
}

"Corresponding author: Laura Donato, Department of Legal Medicine University of Rome "Sapienza”, Italy, Tel: +39 3473821230; E-mail: donato.laura@gmail.com Received date: July 21, 2016; Accepted date: August 29, 2016; Published date: September 06, 2016

Copyright: @ 2016 Donato L, et al. This is an open-access article distributed under the terms of the Creative Commons Attribution License, which permits unrestricted use, distribution, and reproduction in any medium, provided the original author and source are credited

\begin{abstract}
During a forensic investigation, the determination of age at death is typically based on the level of skeletal development. Cranial sutures may help a forensic investigator to determine age at death since there is a predictable interval of age linked to their obliteration. The progression of the obliteration is divided in four stages (from 0 to 3 ), with the last stage indicating complete obliteration, and specific locations on the sutures are considered most useful for the estimation of age at death. However as more of the sutures are obliterated, the traditionally reported interval of age at death grows wider, with a complete obliteration of the sutures referred to a range of 34 to 76 years. Thus one would expect that the cranial sutures of an older person should be completely obliterated. When completely closed, which should happen over the age of 80 years, the sutures nearly disappear and at the last level of obliteration they are no longer visible, in this preliminary study, the authors analyzed a sample of 100 skull photographs taken during post mortem examinations. This study is focused on a macroscopic study of sagittal and coronal sutures. In some cases, the complete obliteration of cranial sutures was visible for individuals with age ranging from 60 to 70 years old. In particular the authors observed the presence of sutures that were not completely obliterated in subjects aged more than 70 years. The aims of this study were to draw attention to these features; to avoid misinterpretation about the age of skeletal remains; and to offer evidence that these criteria may not be reliable for forensic investigation, at least until further study and recalibration to known data.
\end{abstract}

Keywords: Cranial; Sutures; Forensic; Ectocranial; Neurocranium; Bivariate

\section{Introduction}

In the forensic context, interest is often focused on cranial sutures due to their usefulness in the determination of age at death. The level of closure shown by the sutures is associated with an age interval related to age at death. The method of Meindl and Lovejoy established determination of age at death by evaluating the level of obliteration of each ectocranial suture. This level is calculated by assigning a value between 0 and 3, starting from completely opened suture (0), less than $50 \%$ obliteration (1), more than $50 \%$ obliteration (2), or complete obliteration (3). Once each ectocranial suture is evaluated, scores are summed to compute a composite score, which is then used to assign an interval of age. This method experiences problems with both accuracy and precision of the determined age at death. By observing ectocranial sutures during autopsy activities, the authors focus their attention on the morphology of the sutures and their level of obliteration [1-8]. From a sample of 100 individuals, the inaccuracy and imprecision of the Meindl and Lovejoy method was evident. The main goal of this work is to establish that the relationship between the age at death and the level of obliteration of ectocranial sutures is neither reliable nor applicable to the determination of age at death because of the high variability of closure timing.

\section{Materials and Methods}

A sample of 100 neurocranium was photographed during autopsy. The sex and age of each subject was recorded, and each suture was analyzed using the Meindl and Lovejoy method. A score between 0 and 3 is assigned to each suture depending on the level of obliteration: completely opened suture (0), less than $50 \%$ obliteration (1), more than $50 \%$ obliteration (2), or complete obliteration (3). Only the coronal, sagittal, and bregma sutures were considered. These sutures are easily observed during autoptical examination. A summary score was calculated and the authors examined this score's association with the age at death (Figure 1).

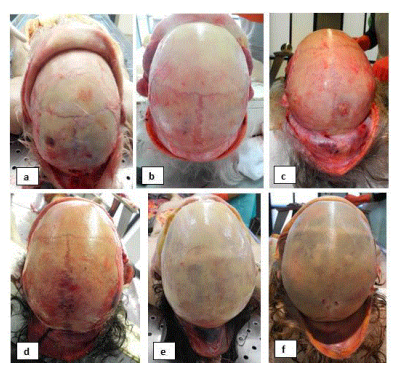

Figure 1: a) 86 years old, b) 75 years old, c) 66 years old, d) 26 years old male, e) 30 years old female, f) 36 years old female. 
Citation: Donato L, Cipolloni L, Ozonoff A, Luca AD (2016) A Preliminary Study of the Relationship between Obliteration of Cranial Sutures and Age at Time of Death. Biol Syst Open Access 5: 163. doi:10.4172/2329-6577.1000163

Page 2 of 3

\section{Results}

The level of obliteration of the coronal, sagittal and bregma sutures was analyzed and the three graphics show the homogeneity of the results. The degree of obliteration does not appear to be strongly associated with age $(\mathrm{p}=0.16)$ and it is necessary to consider a huge interval of age. Figure 1 illustrates similar levels of suture obliteration in both an elderly and a young subject (Table 1 and Figures 2 and 3). This demonstrates that the obliteration of the ectocranial sutures does not determine an accurate age of skeletal remains, including the cranial vault. Figure 1 demonstrates the observed range of ages across composite scores, illustrating little predictive value regarding age at the moment of the death. Notably, Table 1 demonstrates no linear trend between mean age and levels of obliteration. Clearly, the composite scores obtained by the single suture obliteration extent provide excessively wide age ranges. As an example, observed ages for skulls with composite score 3 ranges between 17 and 86 years (mean age 50.2 years), while ages for composite score 9 ranges from 36 to 78 years (mean age 52.1 years). These results underline the inadequacy of this method to estimate age at time of the death.

\begin{tabular}{|c|c|c|c|c|c|c|c|}
\hline Composite Score & No. & Mean Age & Standard Dev & Range & Males & Females & Estimated Age Range \\
\hline 3 & 33 & 50,2 & 24,0 & $17-86$ & 23 & 10 & $26.2-74.2$ \\
\hline 4 & 11 & 46,3 & 22,8 & $19-82$ & 6 & 5 & $23.4-69.1$ \\
\hline 5 & 13 & 42,2 & 12,9 & $25-73$ & 7 & 6 & $29.2-55.1$ \\
\hline 6 & 20 & 60,9 & 16,7 & $29-87$ & 17 & 3 & $44.2-77.7$ \\
\hline 7 & 10 & 56,6 & 15,1 & $40-80$ & 6 & 4 & $41.5-71.7$ \\
\hline 8 & 4 & 55 & 18,3 & $39-75$ & 2 & 2 & $36.7-73.3$ \\
\hline 9 & 9 & 52,1 & 16,0 & $36-78$ & 5 & 4 & $36.1-68.1$ \\
\hline Bregma Value & No. & Mean Age & Standard Dev. & Range & Males & Females & Estimated Age Range \\
\hline 1 & 41 & 48,5 & 23,4 & $17-86$ & 28 & 13 & $25.1-72.0$ \\
\hline 2 & 43 & 53,7 & 18,4 & $25-87$ & 29 & 14 & $35.3-72.1$ \\
\hline 3 & 16 & 53,5 & 15,6 & $36-78$ & 9 & 7 & $37.9-69.1$ \\
\hline Coronal Value & No. & Mean Age & Standard Dev. & Range & Males & Females & Estimated Age Range \\
\hline 1 & 44 & 49,8 & 23,1 & $17-86$ & 29 & 15 & $26.7-72.8$ \\
\hline 2 & 43 & 52,9 & 18,6 & $20-87$ & 30 & 13 & $34.3-71.5$ \\
\hline 3 & 13 & 53,2 & 15,2 & $36-78$ & 7 & 6 & $38.0-68.4$ \\
\hline Sagittal Value & No. & Mean Age & Standard Dev & Range & Males & Females & Estimated Age Range \\
\hline 1 & 49 & 48,1 & 22,6 & $17-73$ & 31 & 18 & $25.4-70.7$ \\
\hline 2 & 34 & 55,4 & 18,1 & $19-75$ & 25 & 9 & $37.3-73.5$ \\
\hline 3 & 17 & 53,9 & 15,7 & $39-78$ & 10 & 7 & $38.2-69.6$ \\
\hline
\end{tabular}

Table 1: Linear trend between mean age and levels of obliteration. 


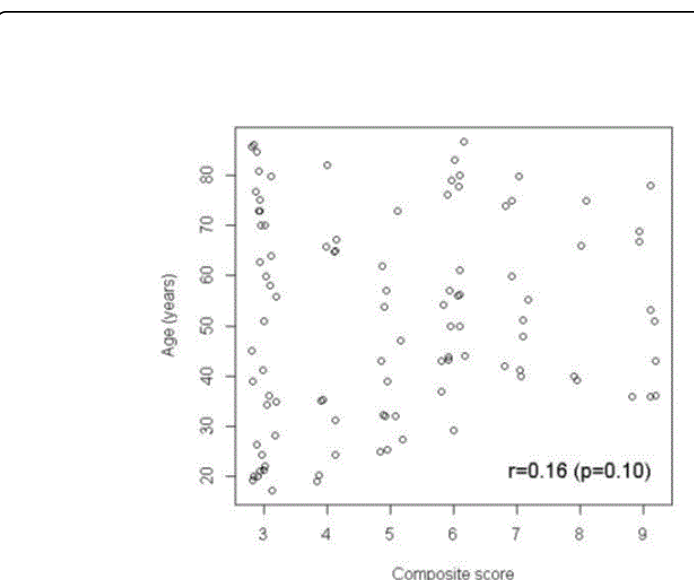

Figure 2: Bivariate scatter plot illustrating relationship between composite score and age at death (Data have been jittered for display purposes)

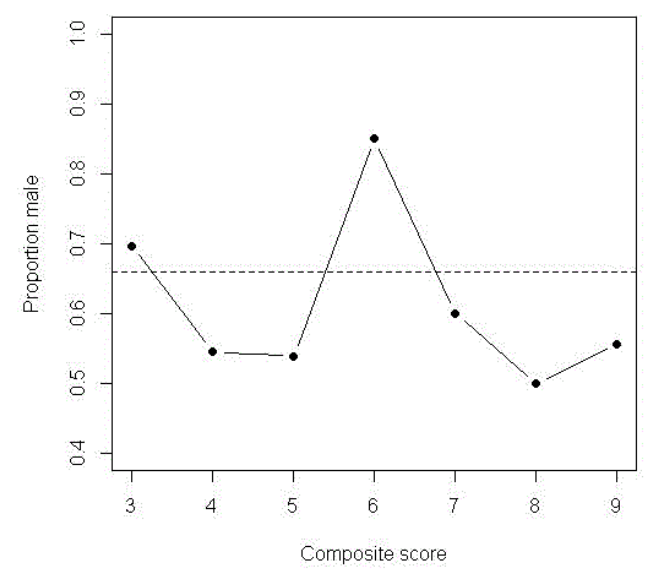

Figure 3: Relationship between composite score and sex.

\section{Conclusion}

The results of this preliminary analysis highlight the high level of imprecision when determining age at death by the analysis of suture obliteration. When determining age at death from skeletal remains, the authors recommend using multiple methods rather than relying only upon suture obliteration. Evidence for this recommendation is made clear when comparing the skull photos of the 86 year old man versus the 26 year old man in Figure 1. The level of suture closure between these two subjects is very similar and can easily be misunderstood. Of course this is a preliminary study and it is necessary to collect additional data to strengthen these recommendations [8-13].

\section{Acknowledgement}

Thanks to Mariarosaria Aromatario MD, who supplied data in order to enrich the case records.

\section{References}

1. Wolff K, Hadadi E, Vas Z (2013) A novel multidisciplinary approach toward a better understanding of cranial suture closure: The first evidence of genetic effects in adulthood. Am J Hum Biol. 25: 835-843.

2. Lynnerup N, Jacobsen JC (2003) Brief communication: age and fractal dimensions of human sagittal and coronal sutures. J Phys Anthropol 121: 332-336.

3. Opperman LA (2000) Cranial sutures as intramembranous bone growth sites. Dev Dyn 219: 472-485.

4. Obert M, Schulte-Geers C, Schilling RL, Harth S, Klaver M, et al. (2010) High-resolution flat-panel volumetric CT images show no correlation between human age and sagittal suture obliteration-independent of sex. Forensic Sci Int 200: 180.e1-12

5. Beckett JS, Brooks ED, Lacadie C, Vander Wyk B, Jou RJ, et al. (2014) Altered brain connectivity in sagittal craniosynostosis. J Neurosurg Pediatr 13: 690-698.

6. N'Guyen T, Gorse FC, Vacher C (2007) Anatomical modifications of the mid palatal suture during ageing: A radiographic study. Surg Radiol Anat 29: $253-259$

7. Khorasani M, Barzi MH, Derakhshan B (2013) Correction of maxillofacial deformities in a patient with unilateral coronal craniosynostosis (plagiocephaly): A case report and a review of iteratures. J Dent (Tehran) 10: 478-86.

8. Heuze Y, Boyadjiev SA, Marsh JL, Kane AA, Cherkez E, et al. (2010) New insights into the relationship between suture closure and craniofacial dysmorphology in sagittal non-syndromic craniosynostosis. J Anat 217: 85-96.

9. Derderian CA, Wink JD, Cucchiara A, Taylor JA, Bartlett SP (2014) The temporal region in unilateral coronal craniosynostosis: A volumetric study of short- and long-term changes after fronto-orbital advancement. Plast Reconstr Surg 134: 83-91.

10. Obenson K (2015) Unusual diastatic separation of the sagittal suture: Avoiding confusion with inflicted head trauma. J Forensic Leg Med 30: 14-15.

11. Jayaprakash PT, Srinivasan GJ (2013) Skull sutures: Changing morphology during preadolescent growth and its implications in forensic identification. Forensic Sci Int 229: 166.e1-13.

12. Jooste N, L'Abbé EN, Pretorius S, Steyn M (2016) Validation of transition analysis as a method of adult age estimation in a modern South African sample. Forensic Sci Int

13. Boyd KL, Villa C, Lynnerup N (2015) The use of CT scans in estimating age at death by examining the extent of ectocranial suture closure. J Forensic Sci 60: 363-369. 